\title{
Special Issue of the International Conference on Computational and Experimental Science and Engineering (ICCESEN-2014)
}

Antalya, Turkey, October 25-29, 2014

Editor of the Special Issue of IJCESEN:

Prof.Dr. İskender AKKURT 


\section{Preface}

The special issue of "International Journal of Computational and Experimental Science and Engineering (IJCESEN) dedicated to selected articles of "International Conference on Computational and Experimental Science and Engineering" (ICCESEN-2014) held in Kemer-Antalya-TURKEY in the period of 25-29 October, 2014. ICCESEN, established by Prof.Dr. İskender Akkurt in 2014, is a remarkable platform where both computational and experimental work on both science and engineering fields are discussed and shared. Thanks to all invited speakers, scientific and organizing committee (listed below) and surely also all participants and look forward to meet again in future ICCESEN conferences (www.iccesen.org). Thanks also to editor of IJCESEN for collaboration with us for publishing 11 papers in this issue. All manuscripts were subjected to the peer review procedure. We appreciate all the authors and reviewers for their valuable contribution in order to achieve a publication of high scientific quality.

Prof.Dr. İskender AKKURT

Chair and Organizer of ICCESEN-Editor for Special Issue 